\title{
Can $\mathrm{C}$ reactive protein or troponins $\mathrm{T}$ and $\mathrm{I}$ predict outcome in patients with intractable unstable angina?
}

\author{
N P Curzen, D J Patel, M Kemp, J Hooper, C J Knight, D Clarke, C Wright, K M Fox
}

\begin{abstract}
Objective-To determine whether a single blood test for the measurement of $\mathrm{C}$ reactive protein, or troponin $I$ or $T$ concentrations could be used to stratify patients with intractable unstable angina awaiting transfer for coronary angiography by correlating these values with coronary anatomy and transient myocardial ischaemia.

Design-Prospective study.

Setting-Tertiary cardiac unit.

Patients-All patients admitted to their local hospital with ischaemic chest pain, uncontrolled by medical treatment, in whom acute myocardial infarction had been excluded by serial measurement of creatine kinase and lack of $Q$ waves on ECG.
\end{abstract}

Intervention-Coronary angiography and ST segment monitoring for 24 hours.

Main outcome measures-Concentrations of $\mathbf{C}$ reactive protein, troponins $\mathbf{T}$ and $I$, coronary anatomy, presence of transient myocardial ischaemia.

Results-Median C reactive protein, troponin $I$, and troponin $T$ concentrations were $17.1 \mathrm{mg} / \mathrm{dl}$ (4.8 to 203.9$), 0.05 \mu \mathrm{g} / 1$ (0 to 7.8$)$, and $0.0 \mu \mathrm{g} / 1$ ( 0 to 2.51$)$, respectively. Seven patients $(10 \%)$ had normal coronaries and 14, 20, and 31 had one, two, or three vessel coronary disease, respectively. Nineteen $(26 \%)$ had transient myocardial ischaemia, $33(46 \%)$ had complex lesion morphology, and six (8\%) had intracoronary thrombus. Of the three markers, troponin $T$ alone was higher in patients with multivessel disease $(p<0.05)$ and in those with transient myocardial ischaemia $(p<0.05)$, but there was no significant relation between $C$ reactive protein, troponin $T$ or $I$ and lesion morphology or thrombus.

Conclusions-In patients transferred to a tertiary centre with intractable chest pain, $C$ reactive protein and troponin $I$ are not predictive of transient myocardial ischaemia or lesion morphology, both of which are surrogate markers of outcome. Troponin $T$ is, however, raised in patients with multivessel disease or transient myocardial ischaemia. These serum protein assays cannot be used to stratify the risk of patients with unstable angina who are awaiting transfer to the tertiary centre. (Heart 1998;80:23-27)
Keywords: C reactive protein; troponin $\mathrm{T}$; troponin $\mathrm{I}$; unstable angina

Patients with non-Q wave myocardial infarction ${ }^{1-3}$ and unstable angina ${ }^{45}$ are at risk of subsequent acute myocardial infarction and cardiac death. The ability to identify which of the patients in this heterogeneous group are at highest risk of subsequent acute myocardial infarction would allow their appropriate stratification into groups that require immediate, urgent, or routine access to invasive facilities for further investigation and treatment. Unstable angina is the product of a pathophysiological complex that centres upon thrombus formation on an atherosclerotic coronary plaque, embolic occlusion of microscopic intramyocardial vessels, and vasospasm. There is accumulating evidence that this process involves local inflammatory pathways. There is demonstrable local release of vasoactive agents-for example, cytokines such as thromboxane, leukotrienes, interleukins, and endothelin-1; attraction of white blood cells with enhanced adhesion molecule expression $^{6-8}$; activation of clotting cascades and platelets; and defective fibrinolysis. ${ }^{910}$ Markers of endothelial activation and injury, such as von Willebrand factor and tPA, are independent predictors of subsequent acute coronary syndromes in patients with angina. ${ }^{10}$ In addition, concentrations of $\mathrm{C}$ reactive protein, a sensitive but non-specific marker of inflammation, have been reported to be raised in patients with both stable and unstable angina, as well as in acute myocardial infarction. Furthermore, some studies have suggested that the concentration of $\mathrm{C}$ reactive protein correlates inversely with outcome in patients with unstable angina, ${ }^{10-12}$ while others have failed to show such a clear cut relation between the inflammatory marker and the clinical outcome. ${ }^{13}$ Nevertheless, one potential method for identifying high risk unstable angina patients - who should be investigated with greatest degree of priority-is to measure a serum marker of the magnitude of the inflammatory response. One recent study even suggested that a single measurement of $\mathrm{C}$ reactive protein concentration is associated with the frequency of subsequent coronary events in patients with either stable or unstable angina. ${ }^{14}$

An alternative method for stratifying patients with unstable angina is to identify those who have already acquired some degree of myocardial damage or necrosis. Traditionally, in the absence of electrocardiographic features of $Q$ 
wave infarction, acute myocardial infarction has been diagnosed when the serial measurement of cardiac enzymes, most often creatine kinase $(\mathrm{CK})$ or its $\mathrm{MB}$ isoenzyme, shows a significant rise. Those patients with acute ischaemia, but without $Q$ waves or such a rise in $\mathrm{CK}-\mathrm{MB}$ are thus diagnosed as having unstable angina. Recently, however, it has become possible to measure serum concentrations of the cardiac specific proteins, troponins I and T. ${ }^{15}$ Both troponin $\mathrm{T}$ and $\mathrm{I}$ are subunits of the protein complex that serves to regulate the interaction between actin and myosin in myocardial contraction. Several large studies have shown that the concentration of one or other of these troponin molecules in the serum of patients with unstable angina or non- $Q$ wave myocardial infarction was predictive of mortality or of non-fatal acute myocardial infarction. ${ }^{16-19}$ In these studies protein concentrations were measured in the acute phase of presentation and were predictive of clinical outcome under these circumstances. However, conventional treatment for unstable angina in the United Kingdom involves a period of intensive medical treatment (usually involving intravenous infusions of nitrate and heparin), before referral for angiographic assessment if and when symptoms do not settle. The tertiary referral centre therefore receives such patients anywhere between one and several days from the original symptoms. It is known, however, that although the plasma concentrations of troponins $T$ and $I$ are raised within three to six hours after the onset of pain in patients with myocardial damage, they can remain raised in the blood for five to six days following acute myocardial infarction. ${ }^{2021}$

In this study we have tested the hypothesis that it is possible to use either $C$ reactive protein or troponin I or $\mathrm{T}$ concentrations as a means of identifying patients with intractable chest pain who are at the greatest risk of imminent myocardial infarction or death. Specifically, our aim was to establish whether concentrations of these proteins correlate with angiographic lesion extent and appearance, as well as with ST segment shift, both of these indices having previously been shown to have prognostic significance ${ }^{22-26}$ and which we were therefore able to employ as surrogate markers of outcome.

\section{Methods}

PATIENTS

Seventy two consecutive patients were recruited who had been admitted with unstable angina that proved refractory to medical treatment in their local hospital. All patients were transferred to this centre for coronary angiography within 48 hours of their last episode of chest pain. Patients who had ECG evidence of $Q$ wave myocardial infarction or a rise of creatine kinase to more than twice the upper limit of normal were excluded from the study. Patients within six months of percutaneous transluminal coronary angioplasty or coronary artery bypass surgery were also excluded. No positive ECG changes were required for inclusion in the study.
All the patients were treated with nitrate (intravenous or buccal) and heparin (intravenous or subcutaneous) during their trial of intensive medical treatment at the district general hospital. Other antianginal drug treatment was at the discretion of the local consultant cardiologist/physician.

ST SEGMENT MONITORING

Upon arrival at this centre, all patients were immediately fitted with a Holter monitor and underwent at least 24 hours of continuous ST segment monitoring before angiography. Recordings were analysed by the same two operators (CW, DC), and ischaemia was defined as the presence of at least $1 \mathrm{~mm}$ of ST segment shift from the baseline lasting at least one minute. The presence of isolated $\mathrm{T}$ wave changes alone was not accepted as evidence of ischaemia.

\section{ANGIOGRAPHY}

Coronary angiography was performed by a femoral approach in all patients, using biplane imaging. Magnified views were taken of all stenoses, subsequently defined as significant when involving more than $50 \%$ of the extraluminal diameter, as assessed visually by two observers who were blinded to the study data. Lesion morphology was classified according to the Ambrose criteria ${ }^{27}$ for all lesions of greater than $50 \%$ severity. Intracoronary thrombus was defined as either a definite filling defect surrounded by contrast or abrupt vessel closure with irregular and convex margins.

\section{PROTEIN ASSAYS}

All blood samples were taken from a peripheral vein as soon as the patient arrived at this centre and then centrifuged immediately for 10 minutes at $1600 \times g$. Serum was then removed and stored at $-70^{\circ} \mathrm{C}$ until the relevant assays were performed.

\section{$C$ reactive protein assay}

The latex enhanced turbidimetric method (Beckman Synchron CX 7 analyser; Beckman Instruments (UK) Ltd, High Wycombe, Buckinghamshire, UK) was employed. This provides within batch precision of $5 \%$ with a lower detection limit of $0.4 \mathrm{mg} / \mathrm{dl}$ and an upper limit of normal of $1 \mathrm{mg} / \mathrm{dl}$. All samples were assayed in a single batch, which included known normal and raised $\mathrm{C}$ reactive protein samples as internal controls.

\section{Troponin $I$ and $T$ assays}

All samples were analysed together in one analytical batch. Appropriate internal controls were included. Troponin I concentrations were measured using a paramagnetic particle, chemiluminescent immunoassay (Access assay; Sanofi Diagnostics Pasteur, Guildford, Surrey, UK). For this assay the lowest detectable concentration of cardiac troponin I distinguishable from zero with $95 \%$ confidence is $0.03 \mu \mathrm{g} / \mathrm{l}$, with the upper limit of values in a normal population being $0.07 \mu \mathrm{g} / 1$ (manufacturer's datasheet). Coefficient of variance at three different concentrations was less than 
Table 1 Demographic data for the study population

\begin{tabular}{ll}
\hline Age (years) & Mean 63.4 Median 63.7 \\
Male & SD 8.5 \\
Female & $54(75 \%)$ \\
Smoker (current) & $18(25 \%)$ \\
Hypertensive & $45(63 \%)$ \\
Diabetes mellitus & $19(26 \%)$ \\
Hyperlipidaemia & $6(8.3 \%)$ \\
Family history of IHD & $26(36 \%)$ \\
Significant CAD & $32(44 \%)$ \\
\hline
\end{tabular}

CAD, coronary artery disease; IHD, ischaemic heart disease.

$8 \%$. Troponin $\mathrm{T}$ concentrations were measured by an enzyme linked immunosorbent one step sandwich assay using streptavidin and hydrogen peroxide for colorimetric analysis (Enzymun-Test; Boehringer Mannheim Diagnostics, Mannheim, Germany). The lower detection limit is $0.02 \mu \mathrm{g} / \mathrm{l}$, with the normal range lying between 0 and $0.1 \mu \mathrm{g} / \mathrm{l}$, the coefficient of variance being $9 \%$ at $0.35 \mu \mathrm{g} / 1$ and $3.2 \%$ at $5.44 \mu \mathrm{g} / 1$ (manufacturer's datasheet). In both cases, as recommended by the assay manufacturers, any value above $0.1 \mu \mathrm{g} / 1$ was taken to be abnormal.

STATISTICAL ANALYSES

No assumption was made over whether the continuous variables in this study were normally distributed, and data were therefore consistently analysed using the following nonparametric tests: Mann-Whitney U, Wilcoxon rank sum tests, and Kruskal-Wallis one way analysis of variance (ANOVA), as stated at the relevant stage in the text. Probability $(\mathrm{p})$ values of less than 0.05 were taken as being significant.

\section{Results}

CLINICAL CHARACTERISTICS

Seventy two patients were included in the study, of whom $54(75 \%)$ were male and 18 $(25 \%)$ female; their mean age was 62.9 years (range 36.0 to 79.1). The demographic data for this group are given in table 1 .

The median time from admission to the district general hospital to transfer to this centre was 9.0 days (range 0 to 21 ; mean 8.7 ).

\section{RECURRENT ISCHAEMIA}

Nineteen patients $(26 \%)$ had transient myocardial ischaemia on their 24 hour Holter according to the criteria described above.

\section{ANGIOGRAPHIC APPEARANCE}

Seven patients $(9.7 \%)$ had angiographically unobstructed coronary arteries, and 14, 20, and 31 patients had one, two, or three vessel coronary disease, respectively. Three (43\%) of the seven patients with unobstructed coronaries were female, and none was diabetic, compared with $23 \%$ and $9 \%$, respectively, in the group with coronary disease. Thirty three $(46 \%)$ patients had complex lesion morphology and six ( $8 \%)$ had intracoronary thrombus.

C REACTIVE PROTEIN AND TROPONIN I AND T CONCENTRATIONS

The median values (range) of $\mathrm{C}$ reactive protein, troponin $\mathrm{I}$, and troponin $\mathrm{T}$ for the 72 patients were 8.7 (4.8 to 203.9), 0.05 (0 to
7.8), and 0 (0 to 2.5), respectively. Using the Kruskal-Wallis one way ANOvA, there was a significant correlation between troponin $\mathrm{T}$ concentration and number of coronaries diseased $(p=0.03)$, but no such relation was seen with either $\mathrm{C}$ reactive protein $(\mathrm{p}=0.1)$ or troponin I $(\mathrm{p}=0.1)$ concentrations. Troponin $\mathrm{T}$ concentrations were also higher in patients with transient myocardial ischaemia (using Wilcoxon rank sum W test; $p=0.04$ ), but the presence of transient myocardial ischaemia was not associated with a significant rise in either troponin I or $\mathrm{C}$ reactive protein.

No association between concentrations of any of the three measured proteins was found with either lesion complexity or intracoronary thrombus.

\section{Discussion}

The optimal treatment of acute coronary syndromes remains uncertain. In acute myocardial infarction, evidence for the benefit of early thrombolysis remains clear cut, particularly in centres without access to immediate invasive facilities. In patients with non- $Q$ wave myocardial infarction and unstable angina, however, thrombolysis is either of no benefit or is actually detrimental to outcome. ${ }^{28-30}$ Patients with unstable angina represent a high risk subgroup who have ischaemic myocardium that is at risk of irreversible damage. Distribution of resources currently demands that the majority of patients who have been given maximum medical treatment for their chest pain, including intravenous heparin and nitrates, but who do not settle, must wait for transfer to another centre for invasive investigation and treatment. While there is good evidence that measurement in the acute phase of either the inflammatory marker protein, C reactive protein, ${ }^{10-12}$ or the cardiac specific proteins, troponins I and $\mathrm{T},{ }^{15-19}$ can provide some information about clinical outcome in unstable angina, it is still not clear which of the patients waiting for transfer to a tertiary centre should be given the highest priority. In other words, further data are required to identify which patients may benefit from aggressive assessment and treatment and which can be treated conservatively because they are at relatively low risk for subsequent events. Recent data from the FRISC study ${ }^{30}$ and the TIMI IIIb database ${ }^{18}$ suggest that troponin $\mathrm{T}$ and I measurement may be valuable tools with which to attempt this risk stratification. However, as pointed out in the editorial that accompanied the TIMI IIIb report, ${ }^{15}$ an improved understanding of the link between these circulating proteins and coronary anatomy would help to refine this system. It is tempting to postulate that the more unstable a plaque, and the more dynamic and reversible the thrombotic changes that occur overlying that plaque, then the greater would be the degree of inflammation (as indicated by $\mathrm{C}$ reactive protein) and the greater the extent of subclinical myocardial injury (as indicated by the troponin concentrations). This is the theoretical basis of the clinical hypothesis that we addressed in the current study: can a one off measurement of either a marker of inflamma- 
tion ( $\mathrm{C}$ reactive protein) or a sensitive marker of myocardial injury (troponin $\mathrm{T}$ and $\mathrm{I}$ ) be used to identify those patients with refractory angina who are at greatest risk of myocardial infarction and death?

Our study group comprised patients who had no new $Q$ waves on ECG or CK/CK-MB evidence for acute myocardial infarction. There were no specific ECG criteria that these patients had to fulfil to be included, and the only inclusion criterion was that they had to be experiencing ischaemic sounding pain despite maximum medical treatment, and that the most recent episode of this pain was within 48 hours of transfer. We have included patients who were later found to have unobstructed coronary arteries because these patients represent an important subgroup that any risk stratifying test should be able to identify and thereby accord low priority. Our aim was to assess the value of these protein assays on one measurement taken at the time of transfer for angiography. These measurements were therefore being made at a later stage than is the case in other studies, and the median time from district general hospital admission to transfer reflects both the pressure under which these invasive facilities are placed and referral patterns in district general hospitals. Our method involved the assessment of transient myocardial ischaemia and angiographic variables that have previously been shown to represent predictors of clinical outcome by this and other groups, ${ }^{22-26}$ and we have therefore employed these as surrogate measures of outcome.

In this study we showed that in patients transferred to this tertiary centre with intractable chest pain there was an association between the concentration of troponin $\mathrm{T}$ and both the number of coronary arteries with stenoses and the presence of transient myocardial ischaemia, but no such associations were seen with troponin I or C reactive protein. No relation was demonstrable between any of the proteins tested and lesion morphology in terms of Ambrose complexity or intracoronary thrombus. It is likely, therefore, that a single troponin $\mathrm{T}$ measurement would yield some prognostic information in such patients, but neither of the others would be of value for the stratification of risk in this population. It is tempting to speculate that after the initial and acute event precipitating ischaemia, the inflammatory response (causing initial rise in $\mathrm{C}$ reactive protein concentration) had subsided, thus explaining our failure to show a significant correlation between $\mathrm{C}$ reactive protein and outcome. Certainly, previous evidence suggests that $\mathrm{C}$ reactive protein concentrations are raised very early on in the natural course of unstable angina, so that on admission, for example, there is considerable prognostic value in the assay. ${ }^{11}$ One recent study even suggested that a single measurement of $\mathrm{C}$ reactive protein is associated with the frequency of subsequent coronary events in patients with either stable and unstable angina. ${ }^{14}$

The concentrations of both troponin $\mathrm{T}$ and I remain raised in the blood for up to 10 days after an episode involving myocardial necrosis, ${ }^{2021}$ because a large proportion of the total intracellular amount of protein is bound up in myofibrils and requires enzymatic degradation under acidotic conditions in order to be released. It is perhaps more surprising, therefore, that there was not a greater positive correlation between the concentration of these two cardiac specific proteins and our surrogate outcome variables. It is notable that although the troponin I concentrations on admission did provide independent prognostic information about clinical outcome at 42 days in the paper by Antman et $a l,{ }^{18}$ there was no significant association between the concentration and the number of coronaries with disease or angiographic intracoronary thrombus. Our study confirms this lack of association, which represents an important negative finding. It is unclear why there is an association between troponin $\mathrm{T}$ but not troponin I concentrations and coronary disease or transient myocardial ischaemia, although it has previously been established that the release patterns of the two proteins is different following myocardial injury, with troponin $\mathrm{T}$ concentrations describing a characteristic biphasic pattern not shared by troponin $\mathrm{I}^{31}{ }^{32}$ This difference in their release pattern is thought to be a result of the nature of the intracellular compartmentalisation of the two proteins, with troponin $\mathrm{T}$ having a large cytosolic pool in addition to the structurally bound (myofibrillar) component.

There are several limitations of this study. Patient numbers are small and a larger sample may provide more information about such questions as why the concentrations of the two troponins did not show a closer correlation. A second limitation is that the patient sample was selected at different centres and we do not know the precise population size from which this sample was taken. Finally, the time from admission to transfer was surprisingly long, reflecting mainly the pressure for beds in the regional centre and to a lesser extent the desire of local physicians to see their patients treated medically in the first instance. Blood tests and Holter monitoring were performed immediately upon arrival in the tertiary centre and we are assuming that the results obtained represent the results that would be obtained if these tests were performed at the original district hospital.

Our data suggest that a single measurement of any of these proteins (C reactive protein, troponin $\mathrm{T}$, or troponin I) on arrival at the tertiary centre does not provide the physician with an adequate tool with which to stratify such patients with confidence into high and low risk groups.

1 Nicod P, Gilipin E, Dittrich H, et al. Short- and long-term clinical outcome after $\mathrm{Q}$ wave and non- $\mathrm{Q}$ wave myocardial infarction in a large patient population. Circulation 1989;79:528-36.

2 Benhorin J, Moss AJ, Oakes D, et al. Multicenter Diltiazem Postinfarction Research Group. The prognostic significance of first myocardial infarction type (Q wave versus non-Q wave) and Q wave location. F Am Coll Cardiol 1990; 15:1201-7.

3 Aguirre FV, Younis LT, Chaitman BR, et al. Early and 1 year clinical outcome of patients evolving non- $Q$ versus $Q$ wave myocardial infarction after thrombolysis. Circulation 1995;
ming out 91:2541-8 
4 McClellan JR. Unstable angina: prognosis, non-invasive assessment and strategies for management. Clin Cardiol

5 Van Mitenburg-van Zijlt AJM, Simoons ML, Verhoek RJ, et al. Incidence and follow up of Braunwald sub-groups in unstable angina pectoris. $\mathcal{F}$ Am Coll Cardiol 1995;25:128692.

6 Serneri GGN, Abbate R, Gori AM, et al. Transient intermittent lymphocyte activation is responsible for the instability of angina. Circulation 1992;86:790-7.

7 Mazzone A, DeServi S, Ricevuti G, et al. Increased expression of neutrophil and monocyte adhesion molecules in unst

8 Jude B, Agraou B, McFadden EP, et al. Evidence for time-dependent activation of monocytes in the systemic circulation in unstable angina but not in acute myocardial infarction or in stable angina. Circulation 1994;90:1662-8.

infarction or in stable angina. Circulation 1994;90:1662-8.
9 Merlini PA, Bauer KA, Oltrana L, et al. Persistent activation of coagulation mechanism in unstable angina and myocarof coagulation mechanism in unstable an
dial infarction. Circulation 1994;90:61-8.

10 Thompson S, Kienast J, Pyke SDM, et al. Haemostatic factors and the risk of myocardial infarction or sudden death in patients with angina pectoris. N Engl f Med 1995;332 635-41.

11 Liuzzo G, Biasucci LM, Gallimore JR, et al. The prognostic value of C-reactive protein and serum amyloid A protein in severe unstable angina. $N$ Engl f Med 1994;331:417-24.

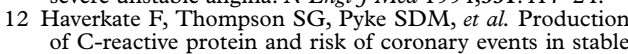
and unstable angina. Lancet 1997;349:462-6.

13 Oltrane L, Merlini PA, Pezzano A. C-reactive protein and serum amyloid A protein in unstable angina [letter]. $N$ Engl f Med 1995;332:399.

14 Haverkate F, Thompson SG, Pyke SDM, et al. Production of C-reactive protein and risk of coronary events in stable and unstable angina. Lancet 1997;349:462-6.

15 Van der Werf F. Cardiac troponins in acute coronary syndromes. N Engl f Med 1996;335:1388-9.

16 Hamm CW, Ravkilde J, Gerhardt W, et al. The prognostic value of serum troponin T in unstable angina. $N$ Engl f Med value of serum trop

17 Ohman EM, Armstrong PW, Christensen RH, et al. Cardiac troponin T levels for risk stratification in acute myocardia ischaemia. N Engl F Med 1996;335:1333-41.

18 Antman EM, Tansijevic MJ, Thompson B, et al. Cardiacspecific troponin I levels to predict the risk of mortality in patients with acute coronary syndromes. $N \mathrm{Engl} f \mathrm{Med}$ 1996;335:1342-9.

19 Lindahl B, Venge P, Wallentin L. Relation between troponin coronary artery disease. Circulation 1996;93:1651-7.
20 Sharley SW, Brunette DD, Ruiz E, et al. An analysis of time delays preceding thrombolysis for acute myocardial infarction. $\mathcal{F A M A} 1989 ; 262: 3171-4$.

21 Adamsill JE, Abendschein DR, Jaffe AS. Biochemical markers of myocardial injury - is MB creatine kinase the choice for the 1990s? Circulation 1993;88:750-63.

22 Patel DJ, Holdright DR, Knight CJ, et al. Early continuous ST segment monitoring in unstable angina: prognostic value additional to the clinical characteristics and the admission electrocardiogram. Heart 1996;75:222-8.

23 Bugiardini R, Borghi A, Pozzati A, et al. Relation of severity of symptoms to transient myocardial ischemia and prognosis in unstable angina. $7 \mathrm{Am}$ Coll Cardiol 1995;25:597-604.

24 Larsson H, Areskog M, Jonasson T, et al. The diagnostic and prognostic importance of ambulatory ST recording compared to a pre-discharge exercise test after an episode of unstable angina or non-Q wave myocardial infarction. Eur Heart f 1995:16:888-93.

25 Freeman MR, Williams AE, Chisholm RJ, et al. Intracoronary thrombus and complex morphology and unstable angina: relation to timing of angiography and in-hospital cardiac events. Circulation 1989;80:17-24

26 Gersch BJ, Braunwald E, Rutherford JD. Chronic coronary artery disease. In: Braunwald E, ed. Heart disease: a textbook of cardiovascular medicine, 5th ed. Philadelphia: WB Saunders, 1997:1335.

27 Ambrose JA, Winters SL, Stern A, et al. Angiographic morphology and the pathogenesis of unstable angina pectoris. $\mathcal{F}$ Am Coll Cardiol 1985;5:609-16.

28 Gruppo Italiano per lo Studio della Streptochasi nell'Infarcto Myocardo (GISSI). Effectiveness of intravenous thrombolytic treatment in acute myocardial infarction. Lancet 1986;i:397-401.

29 ISIS-2. Randomised trial of intravenous streptokinase, oral aspirin, both, or neither among 17,187 cases of suspected myocardial infarction. Lancet 1988;ii:349-60.

30 TIMI IIIB. Effects of tissue plasminogen activator and a comparison of early invasive and conservative strategies in unstable angina and non-Q wave myocardial infarction. Circulation 1994;89:1545-56.

31 Katus HA, Remppis A, Scheffold T, et al. Intracellular compartmentation of cardiac troponin $\mathrm{T}$ and its release kinetics in patients with reperfused and non-reperfused myocardial infarction. Am F Cardiol 1991;67:1360-7.

32 Kratgen JA, Hermens WT, van Dieijen-Visser MP. Cardiac troponin $\mathrm{T}$ release into plasma after acute myocardial infarction: only fractional recovery compared with enzymes. Ann Clin Biochem 1996;33:314-23. 